\title{
Impacts of an urban density gradient on land- atmosphere thermodynamic fluxes across seasonal timescales
}

David Edwin Reed ( $\nabla$ david.edwin.reed@gmail.com )

University of Wisconsin Madison https://orcid.org/0000-0002-8892-1423

Cheyenne Lei

William Baule

Gabriela Shirkey

Jiquan Chen

Kevin P. Czajkowski

Zutao Ouyang

\section{Research Article}

Keywords: Land-Atmosphere Fluxes, Urban Density, Urban Rivers, Sensible Heat Flux, Latent Heat Flux

Posted Date: February 2nd, 2022

DOI: https://doi.org/10.21203/rs.3.rs-195235/v1

License: @ (i) This work is licensed under a Creative Commons Attribution 4.0 International License. Read Full License 


\section{Abstract}

Surface energy partitioning directly connects to the urban heat island effect, which consequently changes regional climate, the health of the urban population, and anthropogenic energy use. In order to quantify land-atmosphere fluxes from urban areas and the impact of the level of intensity of development, we use seven site-years of land-atmosphere flux data from three locations averaged to seasonal timescales. Additionally, all three of our study sites include urban rivers, allowing us to examine urban areas with high and low amounts of potential evapotranspiration. As expected, the urban river decreases the Bowen Ratio of observed fluxes, primarily through lowering sensible heat fluxes. Urban density is positively correlated with sensible and latent heat fluxes when fluxes are coming from non-river areas and negatively correlated with heat fluxes when coming from the urban river. We conclude that effective urban redevelopment guidelines can adopt this knowledge to decrease the urban heat island effect and reach sustainability targets to counteract increased temperatures from climate change.

\section{Introduction}

Urban Heat Island (UHI) effect - a well-documented increase in urban air temperature from increasing amounts of surface sensible heating and the larger thermal inertia of the developed land-surface (Varquez and Kanda, 2018, Arnfield, 2003) - has been a major research focus in urban studies. Embedded within the $\mathrm{UHI}$ is the partitioning of sensible and latent heat, which are the fundamental processes for the magnitude, dynamics and scope of UHI. Here quantifying latent heat fluxes is vital as evapotranspiration (ET) from an urban landscape is generally the largest output of the hydrological cycle over long periods of time (Mitchell et al., 2001), which also determines the level of sensible heat $(\mathrm{H})$ - the remaining portion of available energy. ET from green canopies alter surface energy partitioning and UHI by lowering soil temperatures in the urban environment (Edmondson et al., 2016). How water and energy moves through dense urban settings, urban green spaces, and non-vegetated areas have profound role on many functions of an urban system (Chang et al., 2017).

Urban landscapes are a mosaic of highly contrasting patches across a range of spatial scales, making it difficult to characterize land-atmosphere fluxes due to the non-homogeneity nature of the landscapes. Conventionally, long temporal records are required to quantify trends or changes in fluxes (e.g., ET and H) to capture interannual variability of environmental conditions (Chu et al., 2017), which is a challenge because flux towers in urban systems are relatively rare compared to other land cover types. Meanwhile, spatial coverage can substitute for temporal records (Blois et al., 2013). With a gradient of multiple sites, one can examine the effect of increasing urban density on fluxes. Plausibly, several recent works within the FLUXNET community have also been promoted to connect the mass and energy fluxes with locationspecific patches within the footprint of tower measurements (Xu et al., 2020, Kljun et al., 2015). Here we focus on long-term, 30-minute observations and average data to approximal seasonal timescales to quantify changes between sites and within footprints without losing representativeness. 
In order to quantify land-atmosphere fluxes in urban areas, with a focus on contributions of development intensity, we use seven site-years of eddy covariance data from three cities to create a multi-site synthesis of urban land-atmosphere heat fluxes. Uniquely, all three sites have urban rivers within their flux footprints, allowing us to examine urban areas with high and low amounts of potential evapotranspiration through analysis of air temperature, sensible and latent heat fluxes. Our specific study objectives are to: 1) quantify seasonal changes in thermodynamic fluxes based on environmental air temperature; 2) utilize flux footprint modeling to examine the contributions of urban rivers as evapotranspiration sources on heat flux partitioning; and 3) assess the impact of urban density on thermodynamic fluxes.

\section{Methods}

\section{Data Collection and Processing}

The three urban sites are Toledo, Ohio (Lat: 41.657214, Lon: -83.615806), East Lansing, Michigan (Lat: 42.729345, Lon: -84.473669), and Battle Creek, Michigan (Lat: 42.322809, Lon: -85.187125). Each site was instrumented with eddy-covariance (EC) towers on top of buildings. The Toledo site ran from September 2013 through March 2018, while the East Lansing and Battle Creek sites were both running from December 2017 throughout 2018. The Toledo and East Lansing sites were instrumented with a LI7500 gas analysis (LI-COR Biosciences, Lincoln, NE) and a CSAT3 sonic anemometer (Campbell Scientific, Logan, UT). The tower site at Battle Creek was equipped with an IRGASON (Campbell Scientific, Logan, UT) sensor. These sensors were located at $61 \mathrm{~m}$ (Toledo), $18 \mathrm{~m}$ (East Lansing), and $19 \mathrm{~m}$ (Battle Creek) above ground level, with the building height of $19 \mathrm{~m}, 16 \mathrm{~m}$, and $16 \mathrm{~m}$, respectively. All sensors were located at the edge of the windward side of the buildings, with sensors pointed towards the direction of predominate wind direction. Eddy covariance data were collected at $10 \mathrm{hz}$ for all sites, with average fluxes calculated every 30 minutes.

Data processing for all sites was done through EddyPro v6.2.2 (Biosciences, 2017), with the following corrections applied. Spikes larger than 1\% of the mean were removed (Mauder et al., 2013); and statistical tests following Vickers and Mahrt (1997) were applied. Axis rotation was done following Van Dijk et al. (2004). Density corrections followed Webb et al. (1980). Co-spectra were filtered according to Vickers and Mahrt (1997), while high-pass (Lee et al., 2004) and low-pass frequency (Massman, 2000) effects were corrected. Data quality at each time-step was determined following Mauder and Foken (2006), with data only being retained at each time-step with the highest level of data quality. This data quality process did retain negative latent and sensible heat flux values, and then also negative Bowen ratio values, which were kept in the dataset. While the sites were operating, $49 \%$ of data from Toledo, $36 \%$ from Battle Creek, and $63 \%$ from East Lansing were used in analysis. Footprint estimation was done using the methods of Kljun et al. (2004). For all three sites, peak flux contribution was estimated at an average of $130 \mathrm{~m}$ with $90 \%$ of contributions at $\sim 475 \mathrm{~m}$ distance, therefore, a diameter of $500 \mathrm{~m}$ was applied in our analysis. Data was not $u^{\star}$ filtered or gap-filled. 


\section{Data Analysis}

National Land Cover Database (NLCD) 30 m classification for 2016 was extracted using Google Earth Engine and clipped to a 500 m diameter footprint for each flux tower location. Urban density was calculated for each $30 \mathrm{~m}$ NLCD class as a percent of pixels from the entire footprint. Classification composition was overlain on an ESRI high resolution satellite base maps for visual validation based on our field knowledge. The Battle Creek site had one misclassified pixel "Cultivated Crop" that was reassigned to "Developed, medium intensity" for analysis. In ArcMap, classifications were partitioned into two $180^{\circ}$ hemispheres between urban developed and urban rivers. In MATLAB wind speed and direction data were used to create wind roses in $10^{\circ}$ increments and $1 \mathrm{~m} / \mathrm{s}$ increments from $0 \mathrm{~m} / \mathrm{s}$ to $7 \mathrm{~m} / \mathrm{s}$. Fluxes from each site was binned by both footprint (river vs non-river) as well as by air temperature (10 ${ }^{\circ} \mathrm{C}$ bins). Data were plotted using R software (R Development Team, 2013) as Tukey boxplots, with median, $25^{\text {th }}$ quartile, and $75^{\text {th }}$ quartile, defining the boxes, and lines at \pm 1.5 interquartile range (IQR), and differences were determined on binned data using t-tests. Based on the conclusions of Reed et al. (2018), eddy covariance data are intrinsically time-series in nature and information is known to be lost when data is binned. However, due to the large number of samples in each bin ( $n>2000$, or $n>40$ days of continuous data), there is statistical power to determine differences of $\sim 1 \mathrm{~W} \mathrm{~m}^{-2}$ in heat fluxes between bins, which has a greater precision than normally assumed in EC studies (Wilson et al., 2002). A Levene's test for homogeneity of variance was completed, through which we found that the standard deviations are unequal. Consequently, we completed a Welch ANOVA as it is more robust and is unaffected by unequal variances. The ANOVA was completed using $R$ software (R Development Team, 2013) with the package 'onewaytests'. The Welch ANOVA was completed for latent heat flux (LE), sensible heat flux (H), Bowen Ratio and momentum flux $(\tau)$, followed by correction analysis against air temperature, by study cover type (i.e. River versus Non-River), and urban densities to examined the differences among the sites. A Games Howell multiple comparisons post hoc test was then completed to determine which differences between our study group means were statistically significant. Finally, treatments with the same letter are not deemed significantly different at $p<0.05$.

\section{Results}

Urban and developed areas have high amounts of spatial heterogeneity in their composition within the 250-m footprint (Figure 1; Table 1). East Lansing and Battle Creek are the most heavily developed sites, with $71 \%$ and $63 \%$ of the landscape as medium or high intensity, respectively, while Toledo only had $33 \%$ medium or high intensity. While all sites had urban rivers within their footprints, open water or wetlands were only classified at the East Lansing site as they are too small in the other two sites to dominate a 30$\mathrm{m}$ resolution pixel. When investigating the degree of urban density for both the riverine and non-river portions of the study area, Toledo is the least dense on both footprints (30\% Non-River; $35 \%$ River), while East Lansing has a much higher urban density in its non-river footprint (87\%) compared to Battle Creek's river footprint (65\%) (Table 2 ). The predominant wind directions at Battle Creek is from the west- 
northwest, at East Lansing from the east, and at Toledo from the southwest. The highest wind speeds are evident at Toledo (>7 m/s), followed by East Lansing and then Battle Creek (Figure 2).

When examining the seasonality of fluxes, we show latent and sensible heat fluxes, Bowen ratio and momentum fluxes binned by temperature (Figure 3). All sites had a positive relationship with air temperature and LE $(p<0.05)$, with $\mathrm{H}$ fluxes showing a positive relationship with air temperature at Battle Creek $(p<0.05)$ and East Lansing $(p<0.05)$, and Toledo showing a negative relationship between $\mathrm{H}$ and air temperature $(p<0.05)$. Toledo, the less developed site (i.e., medium/high intensity), had higher variability of $\mathrm{H}$ and $\mathrm{LE}$ fluxes during all seasons than the other two cities. Toledo had a significant number of negative LE fluxes between $20-30^{\circ} \mathrm{C}$ (median $5.7 \mathrm{~W} \mathrm{~m}{ }^{-2}$; IQR -26.7, 59.0) and $30>^{\circ} \mathrm{C}$ (median $-44.5 \mathrm{~W} \mathrm{~m}^{-2}$; IQR -75.6, 71.4), while Battle Creek and Toledo had relatively consistent $\mathrm{H}$ fluxes for most temperature bins ranging around a median of $15.6 \mathrm{~W} \mathrm{~m}^{-2}$; (IQR -3.1, 56.7). Momentum fluxes at Battle Creek and East Lansing averaged a median of $0.1 \mathrm{~kg} \mathrm{~m}^{-1} \mathrm{~s}^{-2}($ IQR $0.02,0.3)$ and were much lower than the Toledo site across all seasons due to the height of the tower $(p<<0.05)$. The Toledo site portrayed a consistent flux of $0.356 \mathrm{~kg} \mathrm{~m}^{-1} \mathrm{~s}^{-2}(\mathrm{IQR} 0.1,0.7)$ over temperature of $<0^{\circ} \mathrm{C}$ to $20-30^{\circ} \mathrm{C}$, with slightly higher variances when temperature was $>30^{\circ} \mathrm{C}$.

By using footprint modeling from each site, we were also able to examine the contributions of urban rivers on land-atmosphere fluxes (Figure 4). In Toledo, there was a marked difference in LE fluxes, with fluxes from the river portion of the footprint being negative (median -2.3 $\mathrm{W} \mathrm{m}^{-2}$; IQR -12.4, 10.6) ( $p<0.05$ ) and fluxes from the non-river area being positive (median $22.3 \mathrm{~W} \mathrm{~m}^{-2}$; IQR 9.5, 41.0) $(p<0.05)$. The two sites with higher amounts of medium/high intensity development did not show significant differences in LE (median $8.2 \mathrm{~W} \mathrm{~m}^{-2}$; IQR 3.4, 17.4). At all sites, there were significant differences between non-river and river footprints for $\mathrm{H}$, with a smaller difference between mean fluxes at the Toledo site $(p<0.05)$. The Bowen ratio is higher for all sites when fluxes are originating from the urban developed (i.e., non-river) areas (Median: non-river 2.0; river 1.1) $(p<0.05)$. There were no significant differences in momentum fluxes between river and non-river type for East Lansing.

When fluxes are explicitly linked to the percentage of urban development within the footprint (Figure 5), the impact of urban density on land-atmosphere fluxes can be quantified. Both LE and H showed similar spatial patterns, with a positive relationship between fluxes and urban density for the non-river and river amount $(p<0.05)$ in East Lansing and Battle Creek. Bowen ratios areas are significant for Toledo and Battle Creek, with Bowen ratios increasing over non-river areas and decreasing over urban rivers $(p<0.05)$. Finally, atmospheric momentum fluxes are also significant in Toledo and Battle Creek, with declines for the entire footprint with higher amounts of urban density $(p<0.05)$.

\section{Discussion And Conclusions}

The first objective was the quantification of thermodynamic fluxes to seasonal forcing. Both $\mathrm{H}$ and LE fluxes displayed positive correlations with air temperature, as one would expect from first principles (Monteith and Unsworth, 2008). With increased air temperature, surface temperature will be higher, 
ultimately increasing upward surface fluxes. Horizontal warm air advection in developing atmospheric boundary layers can explain negative $\mathrm{H}$ fluxes. This is well studied in literature as a driver of urban heat island growth (Ching et al., 1983, Heaviside et al., 2015). Negative heat fluxes and Bowen ratios, which were found at higher frequency at the lower urban density site (i.e., Toledo), are less common in theory (Monteith, 1965, Monteith and Unsworth, 2008), we present them here to show all the data that falls within the highest data-quality level (Biosciences, 2017, Mauder and Foken, 2006). Negative LE fluxes could be oasis effects driven by urban canopies. Taha et al. (1991) found micro-metrological conditions within urban canopies can be up to $6^{\circ} \mathrm{C}$ lower than the surroundings, which would explain the downward recirculation of dry air within the urban environment. We should note that the negative LE fluxes were most common in the least dense site that also had the highest amount of vegetative canopy. Bowen ratios decreased during warming conditions across all sites. While all land-atmosphere fluxes increased during warmer conditions, $\mathrm{H}$ fluxes increased at a faster rate. While urban water cycling is dominated by LE fluxes over long periods of time (Mitchell et al., 2001), urban environments are highly impervious, which leads to reductions in LE fluxes during prolonged warm periods. This finding matches previously reported results, suggesting that $100 \%$ urbanization would decrease evaporation and increase $\mathrm{H}$ fluxes (Dow and DeWalle, 2000).

The second objective was to examine the impacts of urban rivers and evapotranspiration sources on heat flux partitioning. When binned for all sites, contrary to expectations, LE fluxes were lower when coming from the urban rivers (Monteith, 1965, Monteith and Unsworth, 2008). While open water is still a source of water to the atmosphere, higher LE fluxes originated from the developed (non-river) areas of the footprint. This is possible if developed areas have water available for evapotranspiration and if there is more absorbed energy. For LE fluxes originating from non-river areas of the footprints, there is a negative correlation between urban density and LE fluxes likely because urban canopies in lower urban densities are a significant source of water to the atmosphere. To assess the amount of absorbed energy, $\mathrm{H}$ was examined and found to be lower when fluxes originated from rivers, as expected. Decreases in both $\mathrm{H}$ and LE fluxes imply a higher albedo land surface with less total absorbed and reflected energy. Brest (1987) showed albedo and reflectance vary $9-12 \%$ between low and high density urbanized areas and vegetated canopies; and they also demonstrated that lakes have very low reflectance $(\sim 3 \%)$. With urban rivers, very small amounts of river are uncovered by the riparian canopies, negating the impact of lower albedo open water and resulting in higher amounts of lighter vegetation canopies. Altogether, this caused the Bowen ratio to decrease when fluxes were coming from the urban rivers and ultimately lowered the UHI. Because of the reflectance differences between low, medium and high urban densities (Brest, 1987), the impact of rivers on $\mathrm{UHI}$ is expected to vary. It is modified in large part by the physical size of the low reflectance water body and how much the river is directly shaded by vegetation.

Finally, the third objective was to directly quantify the impact of changing urban density on thermodynamic fluxes. Our results clearly show growing urban density increases total energy fluxes (i.e., $\mathrm{H}$ and LE) and Bowen ratios for developed (i.e., non-river) urban areas. More densely developed areas are absorbing and reemitting higher amounts of energy, we assume due to denser areas having lower albedo values or radiation trapping in the complex urban canopy. As expected, we show higher Bowen ratios 
which would increase $\mathrm{UHI}$ in densely developed areas. In the river areas, the opposite is noted with decreased LE, $\mathrm{H}$ and Bowen ratio with increased urban density. Within our sites, Battle Creek was observed to have the highest density at $76 \%$, followed by East Lansing, and then Toledo with the lowest density at $39 \%$. These percentages varied slightly between the different footprints (i.e. River vs Non-River) of our study area, however, clearly shows that urbanization can significantly affect atmospheric fluxes (Figure 5). Variables such as population density, sky-rises and asphalt within the Battle Creek setting may have given rise to observed differences compared to lower density areas, which were surrounded by more waterbodies, greenery, and lower intensity urban surfaces (Figure 1). There has been a recent trend of North American urban areas losing their green spaces, resulting in more brown landscapes (Jin et al., 2019), specifically at lower density urban areas. That trend can be seen here as relatively small differences between $30 \%$ and $60 \%$ urban percentages in heat fluxes.

As discussed above, the urban rivers impact Bowen ratios but are mitigated at highly developed (i.e., nonriver) urban sites. When factoring in variable density of the surrounding areas, the effect of increasing UHI is noted to be high in dense cities. For a more sustainable future, urban areas could focus on re-greening and counterattacking the browning trend (Jin et al., 2019), therein lowering Bowen ratios to cool urban areas and decreasing the amount of anthropogenic energy use.

Caveats apply to results from land-atmosphere fluxes due to the challenging nature of the observations. The footprint model and flux contribution distances at each site are a first-order estimate without a Large Eddy Simulation model at each site therefore, the footprint are only approximations. As long-term observations are regularly exposed to different atmospheric conditions, calculating an effective footprint can be difficult (Mauder et al., 2013). While our urban density percentages have error, we do not believe that the rank-order of sites would change, i.e. Toledo will be the least-dense site no matter if we extend the footprint lengths out to $1 \mathrm{~km}$. Building on this, we sub-set the data to focus on the river and non-river hemispheres within each footprint. However, the statistical differences found in this work are representative of the different land-surfaces across broad seasonal scales.

Another challenge of urban fluxes is making representative local-scale measurements. With observations being located within the roughness sublayer of the urban environment, flux observations have strong dependence on height and instrument location (Christen et al., 2009, Christen and Vogt, 2004). To attempt to address this, we averaged data at larger scales by binning data and focused analysis on urban climate scale questions in place of boundary layer meteorology. By doing so, large amounts of information within the observations (e.g., diel patterns) are overlooked but our objectives of understanding fluxes and drivers on larger seasonal timescales are possible. Finally, radiation, storage heat flux, and anthropogenic heat flux were not measured in the field, which limited the analysis possible.

With these direct measurements of land-atmosphere thermodynamic fluxes along an urban density gradient, this study shows a strong connection between urban density and thermodynamic fluxes. Sensible and LE fluxes varied as a function of both urban density and presence/absence of urban rivers. As expected, the presence of urban rivers decreases UHI effects, particularly at lower urban densities. 
Urbanization and climate change are intrinsically linked with more than half of the world's population living in urban areas. Development of these areas in the future will have large impacts on the earth's climate system (Seto and Shepherd, 2009, Arnfield, 2003). Schneider et al. (2009) defined urban areas as places with more than $50 \%$ of a given landscape unit dominated by the built-up environment and, following this definition, reported urban areas to cover $658,760 \mathrm{~km}^{2}$ of the global land area by using the $500 \mathrm{~m}$ resolution MODIS C5 data, while Ouyang et al. (2019) used Bayesian methods and estimated urban land areas to be between 377,000 and $533,000 \mathrm{~km}^{2}$. Efforts to delineate urban areas vary in their estimates, The Global Rural-Urban Mapping Project estimated urban areas to be 3,524,109 $\mathrm{km}^{2}$ - more than an order of magnitude larger. While efforts to delineate urban areas vary, projections estimate urban land-cover to triple between 2000 and 2030 (Seto et al., 2011) regardless of the exact urban area. This projected increase in urban area has been the focus of previous studies examining the effect of urban density on greenhouse gas fluxes using eddy covariance methods (Nordbo et al., 2012, Velasco and Roth, 2010, Ward et al., 2015). A multi-site observational approach using eddy covariance fluxes, adding to a small number of urban thermodynamic fluxes studies (Christen et al., 2009, Christen and Vogt, 2004, Bergeron and Strachan, 2012, Grimmond and Oke, 1995).

With additional observational findings, better informed policy decisions can be made. With more than half of the world's population living in urban areas, coupled with the increasing rate of urbanization across the globe, sustainable development and redevelopment of urban areas is key to mitigating impacts of urban areas. Changes to surface energy partitioning impacts UHI effects, regional climate, anthropogenic energy use, and human health and stress. Ultimately, redeveloping urban areas in the future while keeping in mind how redevelopment impacts surface reflectance and heat partitioning can help reach sustainability targets and counteract increasing temperatures from climate change.

\section{Declarations}

\section{Funding}

This study was supported, in part, by the NASA Carbon Cycle \& Ecosystems program (NNX17AE16G).

\section{Authors Contributions}

JC led instrumentation of all field sites, with ZO, CL and GS assisting at Battle Creek, ZO, CL, WB, and GS installed the tower at East Lansing, with KPC and ZO assisting at Toledo. DER maintained the Battle Creek and East Lansing sites, while KPC and ZO maintained the site at Toledo. DER collected and calculated final fluxes for all sites. CL, WB, and GS led analysis of the data, DER wrote the first draft of the manuscript and all authors contributed to editing the paper. We would like to acknowledge Yost R. for helping with urban eddy covariance flux processing and Chase Brooke for assisting with East Lansing site development.

Conflictions of Interest 
The Authors have no conflicts for this work to declare

Availability of Data and Material

Data to be uploaded to AmeriFlux data repository

Code Availability

Not Applicable

\section{References}

1. ARNFIELD, A. J. 2003. Two decades of urban climate research: A review of turbulence, exchanges of energy and water, and the urban heat island. International Journal of Climatology, 23, 1-26.

2. BERGERON, O. \& STRACHAN, I. B. 2012. Wintertime radiation and energy budget along an urbanization gradient in Montreal, Canada. International Journal of Climatology, 32, 137-152.

3. BIOSCIENCES, L. 2017. EddyPro Software Instruction Manual. LI-COR Inc., Lincoln, Nebraska, USA.

4. BLOIS, J. L., WILLIAMS, J. W., FITZPATRICK, M. C., JACKSON, S. T. \& FERRIER, S. 2013. Space can substitute for time in predicting climate-change effects on biodiversity. Proceedings of the National Academy of Sciences of the United States of America, 110, 9374-9379.

5. BREST, C. L. 1987. Seasonal Albedo of an Urban-Rural Landscape from Satellite-Observations. Journal of Climate and Applied Meteorology, 26, 1169-1187.

6. CHANG, J., QU, Z., XU, R., PAN, K., XU, B., MIN, Y., REN, Y., YANG, G. \& GE, Y. 2017. Assessing the ecosystem services provided by urban green spaces along urban center-edge gradients. Sci Rep, 7, 11226.

7. CHING, J. K. S., CLARKE, J. F. \& GODOWITCH, J. M. 1983. Modulation of Heat-Flux by Different Scales of Advection in an Urban-Environment. Boundary-Layer Meteorology, 25, 171-191.

8. CHRISTEN, A., ROTACH, M. W. \& VOGT, R. 2009. The budget of turbulent kinetic energy in the urban roughness sublayer. Boundary-layer meteorology, 131, 193-222.

9. CHRISTEN, A. \& VOGT, R. 2004. Energy and radiation balance of a central European city. International Journal of Climatology: A Journal of the Royal Meteorological Society, 24, 1395-1421.

10. CHU, H., BALDOCCHI, D. D., JOHN, R., WOLF, S. \& REICHSTEIN, M. 2017. Fluxes all of the time? A primer on the temporal representativeness of FLUXNET. Journal of Geophysical Research: Biogeosciences, 122, 289-307.

11. DOW, C. L. \& DEWALLE, D. R. 2000. Trends in evaporation and Bowen ratio on urbanizing watersheds in eastern United States. Water Resources Research, 36, 1835-1843.

12. EDMONDSON, J. L., STOTT, I., DAVIES, Z. G., GASTON, K. J. \& LEAKE, J. R. 2016. Soil surface temperatures reveal moderation of the urban heat island effect by trees and shrubs. Sci Rep, 6 , 33708 . 
13. GRIMMOND, C. \& OKE, T. R. 1995. Comparison of heat fluxes from summertime observations in the suburbs of four North American cities. Journal of Applied Meteorology, 34, 873-889.

14. HEAVISIDE, C., CAI, X. M. \& VARDOULAKIS, S. 2015. The effects of horizontal advection on the urban heat island in Birmingham and the West Midlands, United Kingdom during a heatwave. Quarterly Journal of the Royal Meteorological Society, 141, 1429-1441.

15. JIN, J., GERGEL, S. E., LU, Y., COOPS, N. C. \& WANG, C. 2019. Asian Cities are Greening While Some North American Cities are Browning: Long-Term Greenspace Patterns in 16 Cities of the Pan-Pacific Region. Ecosystems.

16. KLJUN, N., CALANCA, P., ROTACH, M. \& SCHMID, H. P. 2015. A simple two-dimensional parameterisation for Flux Footprint Prediction (FFP). Geoscientific Model Development, 8, 3695.

17. KLJUN, N., CALANCA, P., ROTACH, M. W. \& SCHMID, H. P. 2004. A simple parameterisation for flux footprint predictions. Boundary-Layer Meteorology, 112, 503-523.

18. LEE, X., MASSMAN, W. \& LAW, B. 2004. Handbook of Micrometeorology: A Guide for Surface Flux Measurement and Analysis, Kluwer, Dordrecht, The Netherlands.

19. MASSMAN, W. J. 2000. A simple method for estimating frequency response corrections for eddy covariance systems. Agricultural and Forest Meteorology, 104, 185-198.

20. MAUDER, M., CUNTZ, M., DRUE, C., GRAF, A., REBMANN, C., SCHMID, H. P., SCHMIDT, M. \& STEINBRECHER, R. 2013. A strategy for quality and uncertainty assessment of long-term eddycovariance measurements. Agricultural and Forest Meteorology, 169, 122-135.

21. MAUDER, M. \& FOKEN, T. 2006. Impact of post-field data processing on eddy covariance flux estimates and energy balance closure. Meteorologische Zeitschrift, 15, 597-609.

22. MITCHELL, V. G., MEIN, R. G. \& MCMAHON, T. A. 2001. Modelling the urban water cycle. Environmental Modelling \& Software, 16, 615-629.

23. MONTEITH, J. Evaporation and environment. Symp. Soc. Exp. Biol, 1965. 4.

24. MONTEITH, J. L. \& UNSWORTH, M. H. 2008. Principles of Environmental Physics, Amsterdam Elsevier/Acad. Press.

25. NORDBO, A., JARVI, L., HAAPANALA, S., WOOD, C. R. \& VESALA, T. 2012. Fraction of natural area as main predictor of net $\mathrm{CO} 2$ emissions from cities. Geophysical Research Letters, 39.

26. OUYANG, Z., FAN, P., CHEN, J., LAFORTEZZA, R., MESSINA, J. P., GIANNICO, V. \& JOHN, R. 2019. A Bayesian approach to mapping the uncertainties of global urban lands. Landscape and Urban Planning, 187, 210-218.

27. REED, D. E., FRANK, J. M., EWERS, B. E. \& DESAI, A. R. 2018. Time dependency of eddy covariance site energy balance. Agricultural and Forest Meteorology, 249, 467-478.

28. SCHNEIDER, A., FRIEDL, M. A. \& POTERE, D. 2009. A new map of global urban extent from MODIS satellite data. Environmental Research Letters, 4, 044003.

29. SETO, K. C., FRAGKIAS, M., GUNERALP, B. \& REILLY, M. K. 2011. A meta-analysis of global urban land expansion. PLoS One, 6, e23777. 
30. SETO, K. C. \& SHEPHERD, J. M. 2009. Global urban land-use trends and climate impacts. Current Opinion in Environmental Sustainability, 1, 89-95.

31. TAHA, H., AKBARI, H. \& ROSENFELD, A. 1991. Heat-Island and Oasis Effects of Vegetative Canopies Micro-Meteorological Field-Measurements. Theoretical and Applied Climatology, 44, 123-138.

32. VAN DIJK, A., MOENE, A. \& DE BRUIN, H. 2004. The principles of surface flux physics: theory, practice and description of the ECPACK library. Meteorology and Air Quality Group, Wageningen University, Wageningen, The Netherlands, 99, 525.

33. VARQUEZ, A. C. G. \& KANDA, M. 2018. Global urban climatology: a meta-analysis of air temperature trends (1960-2009). npj Climate and Atmospheric Science, 1, 32.

34. VELASCO, E. \& ROTH, M. 2010. Cities as Net Sources of CO2: Review of Atmospheric CO2 Exchange in Urban Environments Measured by Eddy Covariance Technique. Geography Compass, 4, 12381259.

35. VICKERS, D. \& MAHRT, L. 1997. Quality control and flux sampling problems for tower and aircraft data. Journal of Atmospheric and Oceanic Technology, 14, 512-526.

36. WARD, H. C., KOTTHAUS, S., GRIMMOND, C. S., BJORKEGREN, A., WILKINSON, M., MORRISON, W. T., EVANS, J. G., MORISON, J. I. \& IAMARINO, M. 2015. Effects of urban density on carbon dioxide exchanges: Observations of dense urban, suburban and woodland areas of southern England. Environ Pollut, 198, 186-200.

37. WEBB, E. K., PEARMAN, G. I. \& LEUNING, R. 1980. Correction of Flux Measurements for Density Effects Due to Heat and Water-Vapor Transfer. Quarterly Journal of the Royal Meteorological Society, $106,85-100$.

38. WILSON, K., GOLDSTEIN, A., FALGE, E., AUBINET, M., BALDOCCHI, D., BERBIGIER, P., BERNHOFER, C., CEULEMANS, R., DOLMAN, H., FIELD, C., GRELLE, A., IBROM, A., LAW, B. E., KOWALSKI, A., MEYERS, T., MONCRIEFF, J., MONSON, R., OECHEL, W., TENHUNEN, J., VALENTINI, R. \& VERMA, S. 2002. Energy balance closure at FLUXNET sites. Agricultural and Forest Meteorology, 113, 223-243.

39. XU, K., SÜHRING, M., METZGER, S., DURDEN, D. \& DESAl, A. R. 2020. Can Data Mining Help Eddy Covariance See the Landscape? A Large-Eddy Simulation Study. Boundary-Layer Meteorology, 1-19.

\section{Tables}

Table 1: Landscape composition of Battle Creek, Ml; East Lansing, Ml; and Toledo, $\mathrm{OH}$, where Non-River is the area without the river, and Total is the full footprint (i.e., $500 \mathrm{~m}$ diameter). Open water or wetlands were only classified for the East Lansing site because they were undetected at $30-\mathrm{m}$ resolution pixel in Toledo and Battle Creek. 


\section{Land cover}

\begin{tabular}{lllll}
$\begin{array}{l}\text { Non- } \\
\text { River }\end{array}$ & Fraction & River & $\begin{array}{l}\text { Fraction } \\
(\%)\end{array}$ & Total \\
$\begin{array}{l}\text { Area } \\
\left(\mathrm{m}^{2}\right)\end{array}$ & $(\%)$ & $\begin{array}{l}\text { Area } \\
\left(\mathrm{m}^{2}\right)\end{array}$ & & $\begin{array}{l}\text { Area } \\
\left(\mathrm{m}^{2}\right)\end{array}$ \\
\hline
\end{tabular}

Battle Creek, MI

Developed, open space

NA

Developed, low intensity

1740

NA

450

10

450

5

Developed, medium intensity

2520

40

1110

25

2850

32

Developed, high intensity 90

58

1080

24

3600

41

East Lansing, MI

\begin{tabular}{|c|c|c|c|c|c|c|}
\hline Open water & NA & NA & 840 & 18 & 840 & 9 \\
\hline Developed, open space & NA & NA & 180 & 4 & 180 & 2 \\
\hline Developed, low intensity & 540 & 13 & 990 & 21 & 1530 & 17 \\
\hline $\begin{array}{l}\text { Developed, medium } \\
\text { intensity }\end{array}$ & 2940 & 71 & 2310 & 48 & 5250 & 59 \\
\hline Developed, high intensity & 690 & 17 & 390 & 8 & 1080 & 12 \\
\hline Deciduous forest & NA & NA & 30 & 1 & 30 & 0 \\
\hline Woody Wetlands & NA & NA & 30 & 1 & 30 & 0 \\
\hline \multicolumn{7}{|l|}{ Toledo, $\mathrm{OH}$} \\
\hline Developed, open space & 420 & 10 & 1140 & 25 & 1560 & 18 \\
\hline Developed, low intensity & 1800 & 43 & 1770 & 38 & 3570 & 41 \\
\hline $\begin{array}{l}\text { Developed, medium } \\
\text { intensity }\end{array}$ & 840 & 20 & 1170 & 25 & 2010 & 23 \\
\hline Developed, high intensity & 420 & 10 & 450 & 10 & 870 & 10 \\
\hline Deciduous forest & 660 & 16 & 120 & 3 & 780 & 9 \\
\hline
\end{tabular}

Table 2: Portion (\%) of River and Non-River footprints for Battle Creek, East Lansing and Toledo based on urban pixels taken from National Land Cover Database (NLCD) $30 \mathrm{~m}$ classification for each flux tower site. 


\begin{tabular}{llll} 
Percent Urban & East Lansing & Battle Creek & Toledo \\
\hline River & $87 \%$ & $60 \%$ & $30 \%$ \\
\hline Non-River & $57 \%$ & $65 \%$ & $35 \%$ \\
\hline Average Urban & $60 \%$ & $76 \%$ & $39 \%$
\end{tabular}

\section{Figures}

\section{Land Cover}

Open water

$\square$ Developed, open space

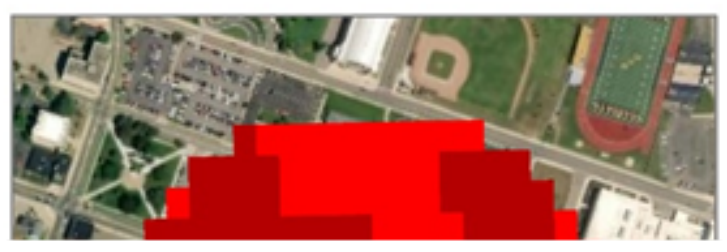

\section{Figure 1}

Landscape composition of Battle Creek, East Lansing, Michigan, and Toledo, Ohio within the footprint of eddy-covariance flux towers. Classification of Battle Creek includes one erroneous pixel of Cultivated Crop, which is visually confirmed as developed, medium intensity. Classification from 2016 NLCD 
(National Land Cover Database) is a 30m Landsat-based land cover database. Base map source: Esri, DigitalGlobe, GeoEye, Earthstar Geographics, CNES/Airbus DS, USDA, USGS, AeroGRID, IGN, and the GIS User Community.

\section{Figure 2}

Wind rose plots of valid 30-minute wind speed for Battle Creek, East Lansing, and Toledo. Wind speeds are binned in $10^{\circ}$ increments centered on $0^{\circ}$ (north). The solid black line on each wind rose indicates the $180^{\circ}$ range considered to be the Non-River or River footprint.

\section{Figure 3}

Boxplots of Latent heat flux (LE), sensible heat flux $(H)$, Bowen Ratio and momentum flux ( $\tau$ ) at Battle Creek, East Lansing and Toledo study sites, binned every $10^{\circ} \mathrm{C}$. Bars represent upper/lower quartiles, mean values are shown by a horizontal line within each bar, and lines at \pm 1.5 IQR. Between-site differences were assessed with one-way Welch ANOVA and post hoc Games-Howell test where ${ }^{*} p<0.05$, and ${ }^{*} p<0.01$. 

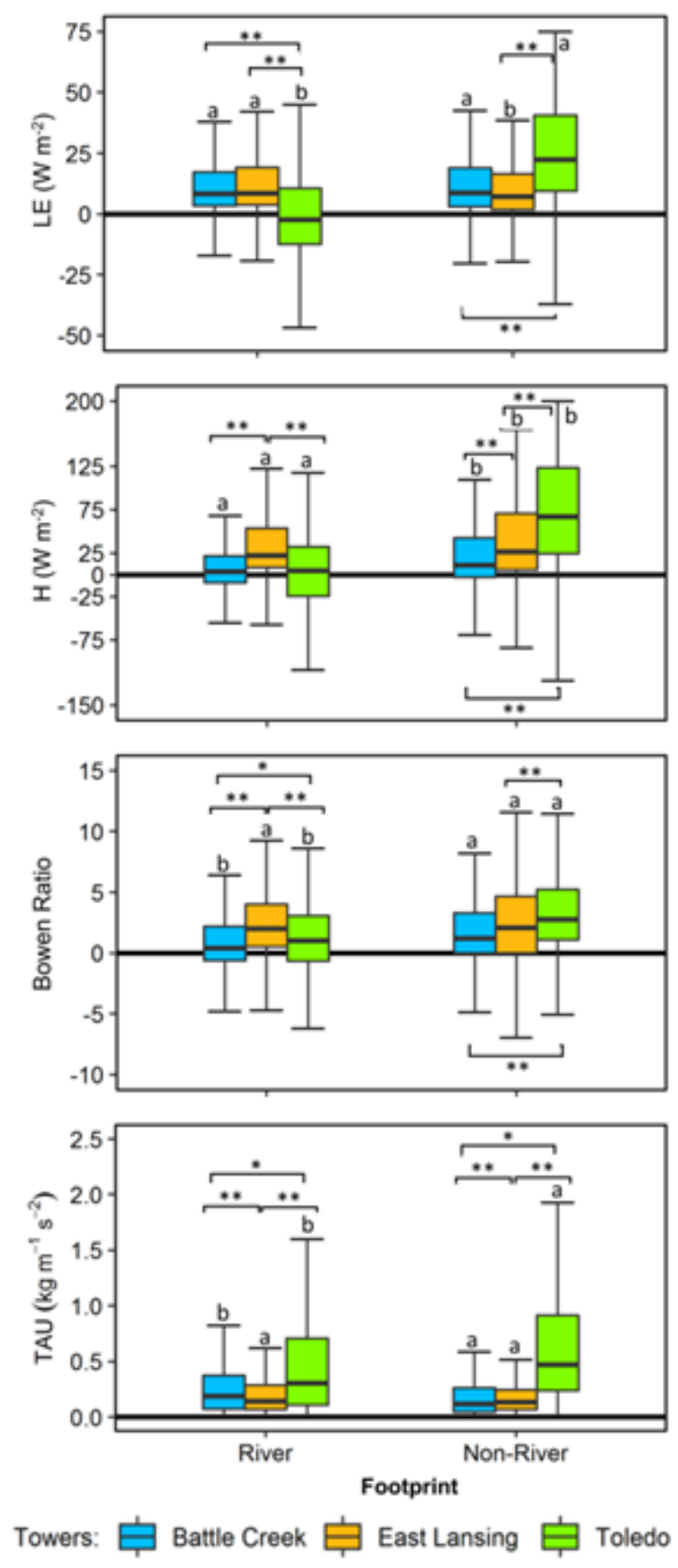

Figure 4

Boxplots of Latent heat flux (LE), sensible heat flux $(H)$, Bowen Ratio and momentum flux ( $\tau$ ) at Battle Creek, East Lansing and Toledo estudy sites, for both River and Non-River components of each study site's footprint. Bars represent upper/lower quartiles, mean values are shown by a horizontal line within each bar, and lines at \pm 1.5 IQR. Between-site and among group differences were assessed by one-way Welch ANOVA and post hoc Games-Howell test where $* p<0.05$, and ${ }^{*} p<0.01$. Lower-case letters show relationship between river and non-river footprints. Treatments with the same letter are not significantly different. 

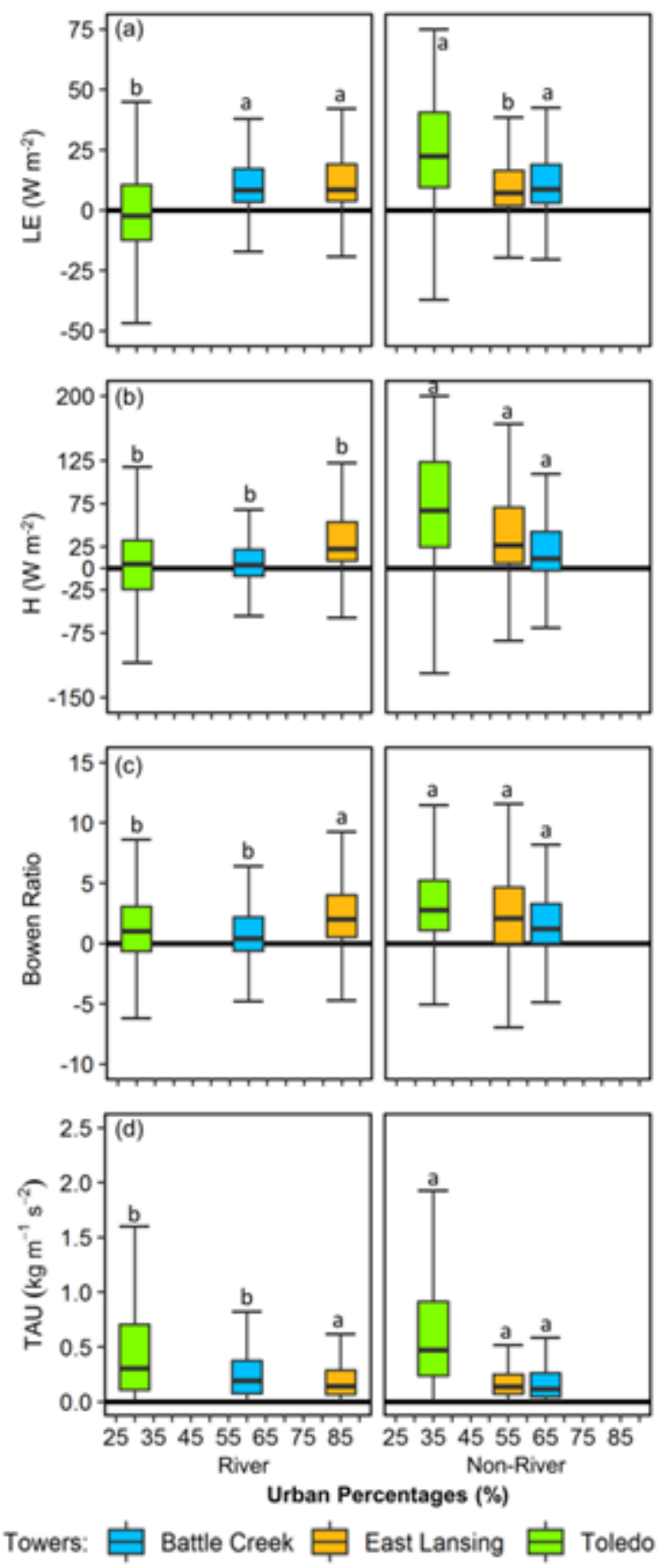

Figure 5

Boxplots of latent heat flux (LE), sensible heat flux (H), Bowen Ratio and momentum flux (Tau) as a function of urban density for each site, for both River and Non-River components of each study site's footprint. Bars represent upper/lower quartiles, mean values are shown by a horizontal line within each bar, and lines at \pm 1.5 IQR. Lower-case letters show relationship between River and Non-River footprints. Treatments with the same letter are not significantly different. 